\title{
Design of learning scenarios based on learning styles according to the KOLB model
}

\author{
Chaimae waladi ${ }^{*}$, Mohammed Lamarti sefian and Mohamed khaldi \\ Laboratory of applied sciences and didactics normal school of Tetouan, Abdelmalek Essaâdi University, Morocco.
}

Global Journal of Engineering and Technology Advances, 2021, 09(01), 050-064

Publication history: Received on 11 September 2021; revised on 15 October 2021; accepted on 17 October 2021

Article DOI: https://doi.org/10.30574/gjeta.2021.9.1.0139

\begin{abstract}
The term learning style refers to the concept of individual differences in which teaching or learning mode is most effective for them. Proponents of learning style assessment believe that optimal teaching requires diagnosing individual learning styles and adjusting teaching accordingly. The assessment of learning styles usually requires people to assess what kind of information presentation they like and/or the mental activities they find most attractive or suitable, although the assessment tools are very diverse, in this article we will propose a pedagogical scenarios 'design adapted to different learning style.
\end{abstract}

Keywords: Learning styles; Pedagogical scenario; Scenario’s Conception; KOLB’s model.

\section{Introduction}

The term learning style refers to the view that different people learn information in different ways. In recent decades, the concept of learning style has become increasingly influential, as understanding learners' learning styles can help promote learning and teaching in several ways. First, teachers can benefit from information about how learners are accustomed to learning, which allows them to better understand and can help interpret or prepare learning materials. In addition, it let learners understand their learning style and showing them their strengths and weaknesses for helping them to understand why learning is sometimes difficult for them and is the basis for developing their weaknesses. Moreover, learners can be supported by matching teaching styles to their learning styles. Providing learners with learning materials and activities that suit their preferred learning style can make learning easier for them [1].

This article explores the impact of learning styles on learner performance. There is enough literature in educational field that shows that activities adapted to learners' learning styles lead to better outcomes for learners. It may lead to the development of educational activities adapted to specific learning styles. [2]

In this article, we describe the strong interest that the concept of learning style has generated among professional educators at all levels of the educational system. We will introduce in the next section a brief overview of learning styles . Then, the concept of the learning scenario according to IMS-LD will be presented. In the Section 3 we will present proposals for learning scenarios according to learning style based on the KOLB model.

\section{Learning styles}

The term learning style refers to the view that different people learn information in different ways. Over the last decades, the concept of learning style has been progressively affected. It appears to be widely accepted not only among educators but also among parents and the public. This acceptance is perhaps not surprising, as providers are actively

\footnotetext{
${ }^{*}$ Corresponding author: Chaimae waladi

Abdelmalek Essaâdi University, Tetouan, Morocco.

Copyright (C 2021 Author(s) retain the copyright of this article. This article is published under the terms of the Creative Commons Attribution Liscense 4.0.
} 
promoting the idea of learning styles, creating many different tests, assessment equipment, and online technologies to identify learners' learning styles and adjust their teaching methods [3].

\subsection{The VAK Model: Fleming's Learning Styles}

Fleming's VISUAL-auditory-kinesthetic (VAK) model is one of the most common and widely used classifications of learning styles. The VAK model provides a simple way to explain and understand learning styles. Fleming believes that learners' styles are divided into three categories [4].

Table 1 The attributes of each Fleming learning style

\begin{tabular}{|l|l|}
\hline Learning style & Attributes \\
\hline Vision & $\begin{array}{l}\text { The learners prefer to learn through observation. They think in pictures. They like visual aids } \\
\text { such as slides, diagrams, and handouts. }\end{array}$ \\
\hline Hearing & The learners prefer to learn by listening. They love lectures, discussions and recordings \\
\hline Kinesthetic & $\begin{array}{l}\text { The learners prefer to learn through the experience of moving, touching and doing. They like to } \\
\text { actively explore the world, such as science projects, structures or construction models and } \\
\text { active experiments. }\end{array}$ \\
\hline
\end{tabular}

\subsection{THE KOLB Learning Styles Model}

Kolb's learning theory defines four different learning styles. Depending on how people perceive and process information.[4] [5].

Table 2 The attributes of each KOLB learning style

\begin{tabular}{|l|l|}
\hline Learning style & Attributes \\
\hline Converters & $\begin{array}{l}\text { The learners prefer to learn by solving problems and performing technical tasks. They are good } \\
\text { at discovering the practical uses of ideas. They like concepts and active experiences. }\end{array}$ \\
\hline Divergents & $\begin{array}{l}\text { The learners prefer to learn through observation, brainstorming and information gathering. They } \\
\text { are imaginative and sensitive. They love practical experience and reflection. }\end{array}$ \\
\hline Assimilators & $\begin{array}{l}\text { The learners prefer to learn by organizing information in a concise and logical order and using } \\
\text { reflective observation. They like abstract modelling and theoretical reasoning. }\end{array}$ \\
\hline Adapters & $\begin{array}{l}\text { The learners prefer to take a hands-on, experiential approach. They are people-centred, hands- } \\
\text { on learning and rely more on perception than logical analysis. They like hands-on experience and } \\
\text { active testing. }\end{array}$ \\
\hline
\end{tabular}

\subsection{The Honey-Mumford's Learning Styles Model}

Honey Mumford's learning styles are very similar to Kolb's. They also defined four different learning styles [4] [6]. 
Table 3 The attributes of each learning style according to Honey-Mumford

\begin{tabular}{|l|l|}
\hline Learning style & Attributes \\
\hline Activist & $\begin{array}{l}\text { The learners prefer the challenges brought by new experiences and activities. They dive straight } \\
\text { into the new experience to learn from them. They are good at problem solving and role-playing, } \\
\text { and they enjoy group discussions. }\end{array}$ \\
\hline Reflector & $\begin{array}{l}\text { The learners prefer to learn by observing and reflecting on what they have observed. They are } \\
\text { prudent people and they will investigate or observe before making promises. They collect and } \\
\text { analyze data before making decisions }\end{array}$ \\
\hline Theorists & $\begin{array}{l}\text { The learners prefer to think about problems step by step. They like complex logical theories } \\
\text { because they tend to analyze and synthesize situations, principles, and other processes. They } \\
\text { usually prefer to listen to lectures, read and make models. }\end{array}$ \\
\hline Pragmatic & $\begin{array}{l}\text { The learners are more willing to accept what they have learned and apply it to see if it is effective. } \\
\text { They like to experiment or apply theory in practice. They love the lab, fieldwork and observation. }\end{array}$ \\
\hline
\end{tabular}

\subsection{The Felder-Silverman Model of Learning Styles}

The Felder-Silverman model examines specific areas of personality that are useful for learning. They are active or reflexive, sensory or intuitive, visual or oral, inductive or deductive, continuous or global. The combination of these styles constitutes personal learning preferences [4] [7].

Table 4 The attributes of each Felder-Silverman learning style

\begin{tabular}{|l|l|}
\hline Learning style & Attributes \\
\hline Sentiment & these learners prefer specific thinking, practice, focusing on facts and procedures \\
\hline Intuitive & these learners prefer design thinking, innovation and focus on theory and meaning \\
\hline Visual & these learners prefer visual representations, images, diagrams and flowcharts \\
\hline Oral & These learners prefer written and oral explanations \\
\hline Active & These learners prefer to experiment and work in groups with others \\
\hline Reflective & These learners prefer to think about problems, work alone or with familiar partners \\
\hline Sequence & these learners prefer linear, orderly thinking and learn in small incremental steps \\
\hline Worldwide & these learners prefer holistic thinking, systemic thinkers and a big leap in learning \\
\hline
\end{tabular}

\subsection{The 4MAT model}

Bernice McCarthy created the 4MAT model. this model determines four learning methods based on the theory of brain superiority [4]

Table 5 The attributes of each 4MAT model learning style

\begin{tabular}{|l|l|}
\hline Learning style & Attributes \\
\hline $\begin{array}{l}\text { Innovative/imaginative } \\
\text { learners }\end{array}$ & $\begin{array}{l}\text { The learners prefer cooperative learning and brainstorming. They are interested in } \\
\text { personal meaning and bonding. }\end{array}$ \\
\hline Analytical learners & $\begin{array}{l}\text { The learners prefer to read and analyze data. They are interested in getting facts to } \\
\text { deepen their understanding of concepts and processes. }\end{array}$ \\
\hline Common sense & $\begin{array}{l}\text { The learners prefer specific experiential learning activities. They're interested in } \\
\text { how things work. }\end{array}$ \\
\hline Dynamic learners & $\begin{array}{l}\text { The learners prefer role-playing games and games. They are interested in self- } \\
\text { managed discoveries and rely heavily on their intuition. }\end{array}$ \\
\hline
\end{tabular}




\subsection{Anthony Gregorc's model}

Anthony Gregorc's model is based on the cerebral hemispheres studies . It is based on the existence of perception and belongs to a continuum rather than extremes [4]

Table 6 The attributes of Anthony Gregorc's model learning style

\begin{tabular}{|l|l|}
\hline $\begin{array}{l}\text { Learning } \\
\text { style }\end{array}$ & Attributes \\
\hline $\begin{array}{l}\text { Specific } \\
\text { sequence }\end{array}$ & $\begin{array}{l}\text { The learners prefer sequence, logical sequence, and follow-up of instructions, predictability of } \\
\text { obtaining facts, practical activities, step-by-step instructions and concrete examples. }\end{array}$ \\
\hline $\begin{array}{l}\text { Specific and } \\
\text { random }\end{array}$ & $\begin{array}{l}\text { The learners prefer to try to find answers, take risks, use their intuition and solve problems } \\
\text { independently. }\end{array}$ \\
\hline $\begin{array}{l}\text { Synthesis } \\
\text { sequence }\end{array}$ & $\begin{array}{l}\text { The learners like to be alone, as structured materials, analyze the situation before making a } \\
\text { decision or action, and use logic to solve or find solutions to problems. }\end{array}$ \\
\hline $\begin{array}{l}\text { Random } \\
\text { Summary }\end{array}$ & $\begin{array}{l}\text { The learners prefer to pay attention to interpersonal relationships and their emotions, listen to the } \\
\text { opinions of others, bring harmony to the group, establish healthy relationships with others and pay } \\
\text { attention to the problems to be solved. }\end{array}$ \\
\hline
\end{tabular}

\subsection{Hermann's cerebral dominance model}

The Herrmann Brain Dominant instrument is based on the idea that one side of the brain dominates the other. Then each party is divide in to two halves of the brain into the first half and second half, forming four parts in the brain. Individuals dominate in one of these four areas, as shown by their personality types [4] [8].

- Quadrant A: Left Cerebral Hemisphere Theorist (Analytical)

- Quadrant B: Organizer of the left limbic system (sequence)

- Quadrant C: Humanists in the Right Limbic System (Interpersonal Communication)

- Quadrant D: Right Hemisphere Innovator (Imaginative).

Table 7 The attributes of Hermann's brain dominance learning style

\begin{tabular}{|l|l|}
\hline Learning style & Attributes \\
\hline Theorists & $\begin{array}{l}\text { The learners prefer lectures, facts and details, critical thinking, textbooks, and reading materials. } \\
\text { They are fact-oriented learners who adopt logical, analytical and quantitative methods for } \\
\text { learning tasks }\end{array}$ \\
\hline Organizers & $\begin{array}{l}\text { The learners prefer to learn through plans, checklists, exercises and steps, policies and problem- } \\
\text { solving procedures. They study sequentially and organized, and the pedagogical exercises are } \\
\text { structured and detailed. }\end{array}$ \\
\hline Humanitarian & $\begin{array}{l}\text { The learners prefer brainstorming, metaphors, illustrations and images, mind mapping and } \\
\text { synthesis, and holistic methods. They are interpersonal, emotional and kinesthetic. }\end{array}$ \\
\hline Innovative & $\begin{array}{l}\text { The learners prefer cooperative learning and group discussions, role-playing and dramatization. } \\
\text { They take a holistic approach and are very intuitive. }\end{array}$ \\
\hline
\end{tabular}

\section{Pedagogical scenarios}

Paquette in 2002, sees that with the help of pedagogical scenarios, designers can establish links between the information sources and the different participants. The designer foresees the types of communication, educational strategies and modes of cooperation between actors designing educational programs. The learning scenario is a series of activities intended for the learner and organized into a coherent whole. The proposed activities are complemented by tools (instrument-input) to support the activities and tools (products) that the learner wants to produce [9].

Also in 2002, for Daele and his collaborators, pedagogical scenario is considered as the result of learning activities designing process that takes place in a given period and leads to program implementation. Therefore, in a scenario, we 
find goals, learning activity plans, timelines, learners'job descriptions, definitions, layouts, and assessment methods during the design process [10].While Lando in 2003, defines pedagogical scenarios as processes, learning activities, goal setting, task planning, description and methods of evaluating learners' tasks [11].

According to Pernin and Lejeune in 2004, a scenario is defined as a description of a priori and a posteriori. It is designed to specify roles, activities, and resources for manipulating knowledge. It aims to use a precise set of knowledge to demonstrate learning. Knowledge and tools related to the execution of activities. Services and results [12].

While Guéraud in 2006, sees that a pedagogical scenario has a triple role: it precisely defines the activities offered to learners on interactive educational objects OPI (Interactive Educational Objects), it also specifies how the progress of learners will be controlled during an activity, it finally determines the pedagogical help provided automatically according to your progress [13].

\subsection{Pedagogical scenario according to IMS-LD}

The beginning of 2000s, a new trend has bring an interest in teaching models in order to respond efficiency to technology integration into education and training. In fact Koper in 2001, proposes a vision that differs from the philosophical approach. He Affirms that the key to the success of a learning environment is not the objects of knowledge, but the activities related to them. It is based on a conceptual meta-model, and it is recommended to use a pedagogical modelling language to describe learning ,so that you can define the relationship between the objectives, activities carried out and the environment and content required to establish a learning environment based on the knowledge or skills and participants in learning [14]. In this last work, autor was embodied in the first Educational Modeling Language (EML) specification, which greatly inspired the Instructional Management System Learning design(IMS) learning design specification in 2002. IMS LD is a pedagogical modelling language.) provides a framework to ensure the interchangeability and interoperability of learning materials and units of learning materials in stages while taking into account the diversity of teaching methods [15].

\subsection{Learning unit with IMS-LD}

The IMS-LD focuses on the staging of resources in a training process, more than the aggregation of resources, whose pedagogical objects are not centrated to the learning process but to the activities associated with them. Therefore, this calls into question some aspects of the LOM (Learning Object Metadata (LOM) is a schema for describing teaching and learning resources). The activity is put at the center of the process, it is defined as a task with a specific pedagogical objective, it is carried out by a certain number of stakeholders who hold different roles (teachers, tutors, etc.) in a certain environment and relying on a certain number of resources, digital or not, and including educational objects, documentary resources, simulations. The main concept of learning design is called "method", which is an element that can coordinate the activities of each role in the relevant environment to achieve certain learning objectives based on prerequisites. It is an element that defines the learning process and refers directly or indirectly to all other concepts [16]

\subsection{Taxonomy of pedagogical scenarios with IMS-LD according to KOPER}

A learning scenario represents a priori or posterior a description of learning situation or unit of learning processes, which is designed to specify a precise set of roles, activities and specialized knowledge. These resources, tools and services are necessary to carry out activities [17]. The diagram in the following figure illustrates this conception [18]

\subsubsection{Predictive scenarios}

Predictive scenarios refer to scenarios established a priori for designers to establish learning conditions, whether or not they are tested by digital technology. The definition of the prediction scheme can pursue several additional objectives: To rationalize the design which designers will be able to define the learning situations and to provide them with methodological advice. Designers can be either experts who participate in the process of industrialization of training, or teachers or trainers. They can change their practices and improve the effectiveness of the learning situation specifically by allowing the responsible staff to change their practices in a more personalized way. Their implementation and monitoring to establish a clear framework, through clear learning objectives and the structure of the activities in which they engage, to better guide learners in carrying out the activities to be carried out and give them the means to carry them out, and to empower learners by clarifying the learning objectives and the structure of the activities to be carried out [19]. 


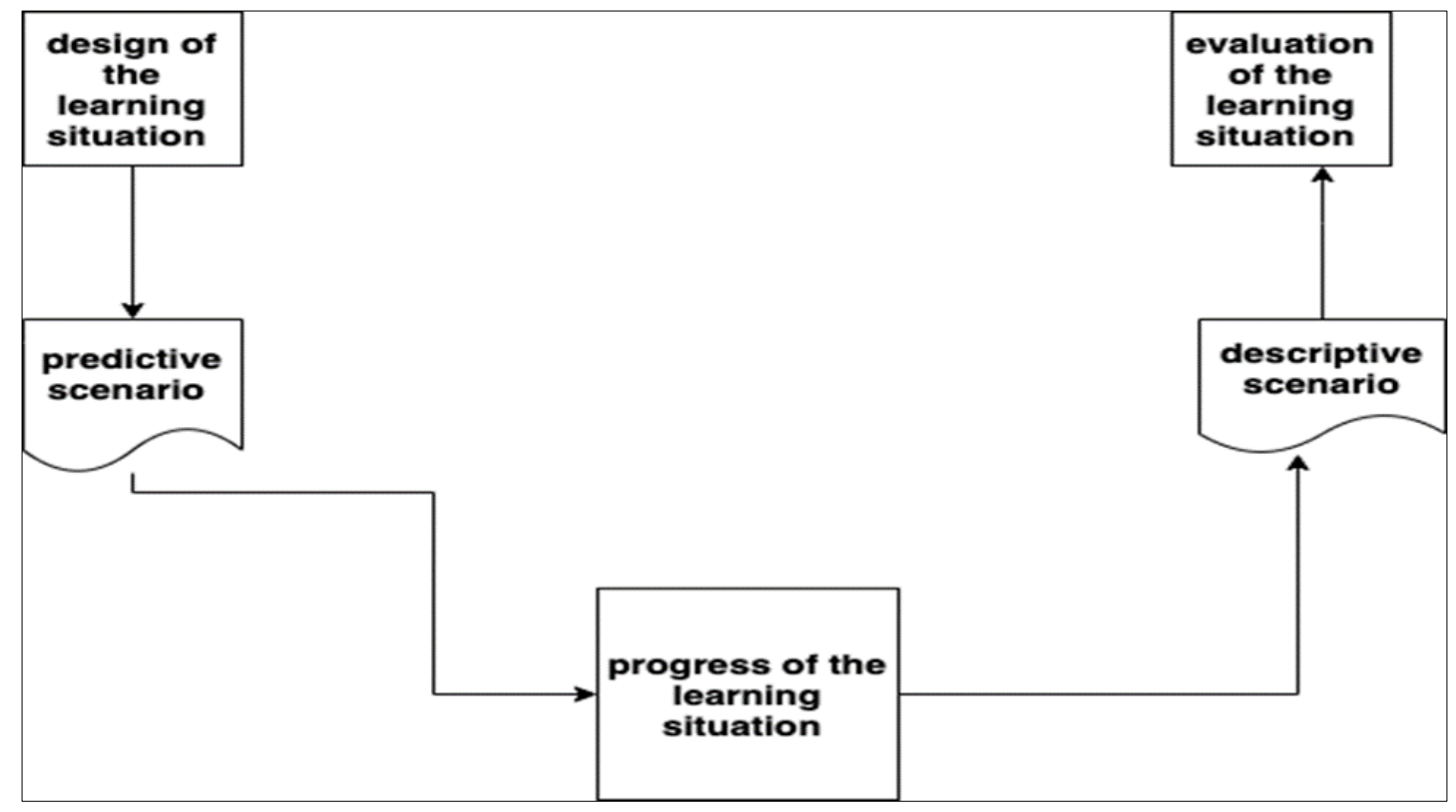

Figure 1 Description a priori or a posteriori of a learning situation

\subsubsection{Descriptive scenarios}

Descriptive scenarios are scenes that describe the actual development of the learning situation of the posterior, in particular the traces of the actors' activities traces [17]. The uses of descriptive scenarios can pursue different objectives

- Pedagogical assessment of learning: use learning events and traces encountered in real-life situations to infer or test assumptions about the effective distribution of knowledge. This method is often used in the field of experimental psychology;

- Help assess learners by analyzing all collected traces and comparing them with predefined models;

- Help to establish personal profiles and allows for personalized learning.

\subsubsection{Criteria for pedagogical scenarios}

Based on the work of Pernin, Lejeune, we will establish a taxonomy of scenarios based on a set of criteria, inspired from following criteria [18]

The granularity of a scenario

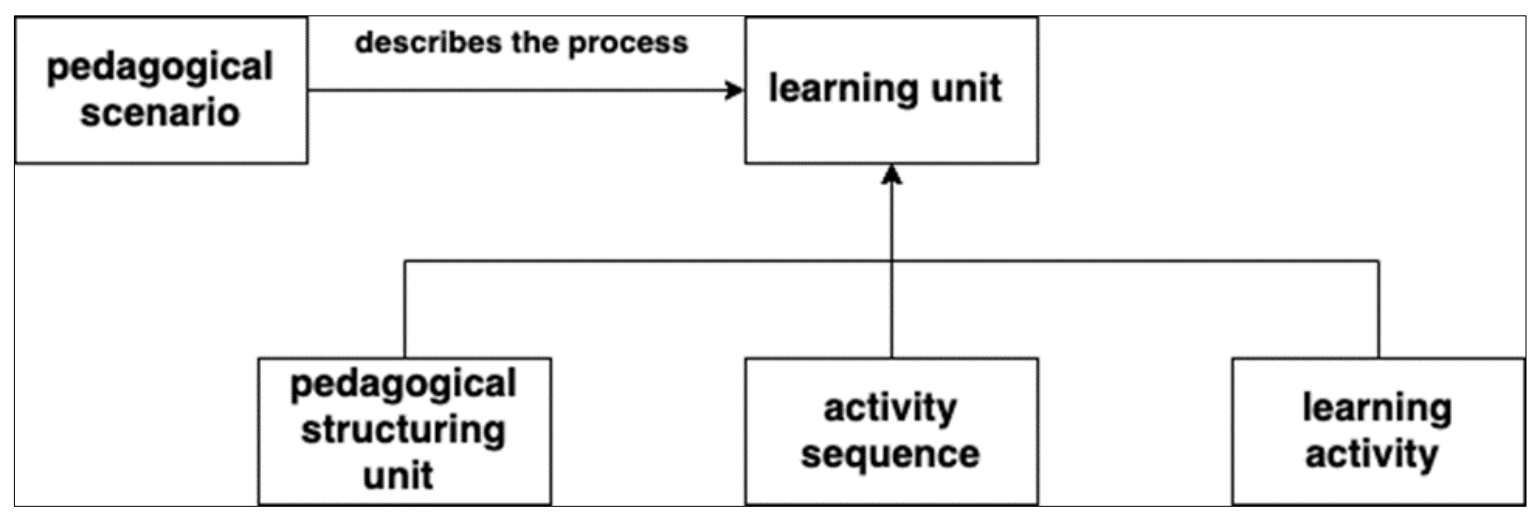

Figure 2 Scenario and granularity of learning unit

The granularity of a learning unit can vary and we can distinguish at least three levels: basic activities, sequences of activities and units of teaching structure. 
- Basic activities: correspond to the optimal granularity of the learning situation, in which one or more participants (learners, trainers, instructors, etc.) usually act in a defined environment and have a short action time or interaction in a continuous defined duration. Core activities can pursue specific learning objectives or contribute to them only by integrating them into a structured sequence.

- Activity sequences: corresponds to the average granularity of the learning situation. In this process, certain basic activities or sequences are organized to achieve the learning objectives determined according to knowledge or skills. The organization must be able to express the relationship between sequence and parallelism, describe the conditions of the sequence and specify the relevant data flow process.

- Unit of pedagogical structure: corresponds to the highest granularity of the learning situation. For this situation, a set of teaching sequences are combined to form a logical unit around a given learning theme and a specific audience.

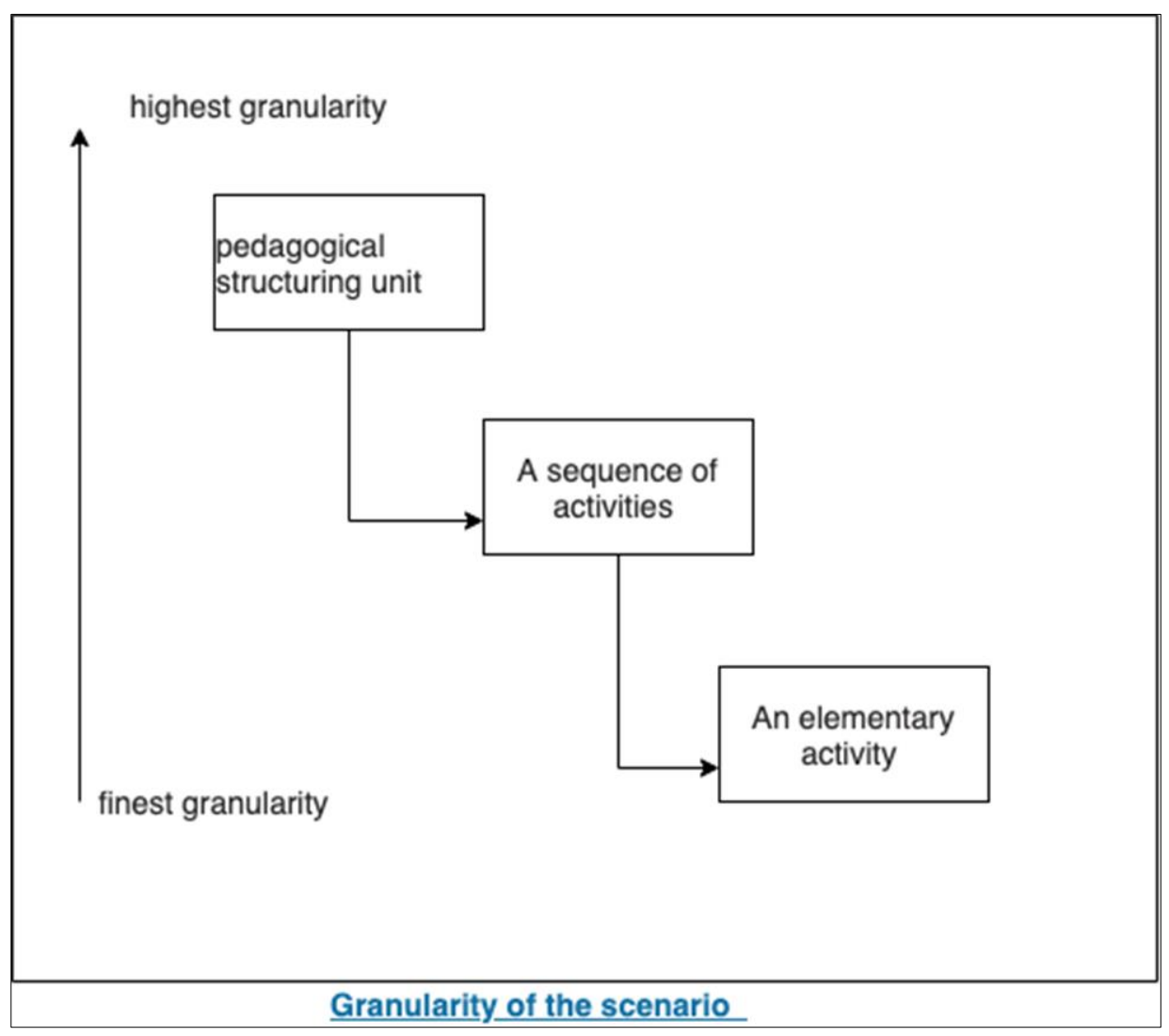

Figure 3 Granularity of the pedagogical scenario

Degree of scenario constraint

The description learning situation to realize is too imprecise:

- A constrained scenario accurately describes the activity to be performed. This situation makes the learner's initiative in action weak, usually related to the rationalization of assessment and the adoption of behaviourist methods;

- An open scenario describes the activities to be realized with an approximate scheme, giving participants in the learning state, great liberty to organize activities or determine their courses. In particular, open scenes must allow the possibility of delegating potentially unexpected choices to human actors to be expressed, and these choices will not decrease the quality of the learning objectives pursued. Generally, open situations are related to constructivist or social constructivist learning methods;

- An adaptable scenario is an open scenario, which is characterized in that participants can modify or complete it in the learning situation, and then they can remember it for later use. 


\section{Scenario customization degree}

As Koper pointed out, a pedagogical modelling language must be able to adapt content and activities to each learner according to thier preferences, a priori knowledge, pedagogical needs or the pedagogical environment [20]. This leads us to introduce the concept of learning profiles and adaptive scenarios.

- A profile is a set of information about a learner or group of learners that is entered, collected or deducted after one or more educational activities. This information can be related to knowledge, skills, design, presentation or ergonomic style;

- A general scenario is a predictive schema whose execution is always the same from one session to another;

- An adaptive scenario is a predictive scenario that take into account the standard configuration file and allows the conditional execution of several custom scenarios that manipulate resources through the nature of the proposed interaction (feedback, processes, etc.) or knowledge distinguish offers

Formalization of a scenario Degrees

To formalize a scenario, four points must be taken in consideration:

- $\quad$ The pedagogical modelling language: can clearly express different scenarios, whether abstract or/and specific, can be reused in different contexts;

- An informal scenario: Teachers can design informal scenarios based on experience rules according to thumb rules of for their teaching;

- A formalized scenario: Official programs use an educational modelling language to promote sharing and reuse it among communities of practice;

- An automatable scenario is an automating. It is a formal solution that uses a "computable" educational modelling language to ensure partial or total automation at different stages of its life cycle (creation, operation, evaluation).

Reification of scenarios Degree :

We use the following mind map to summarize this taxonomy, which must be allowed to describe the pedagogical scenario at a specific point in time [18]:

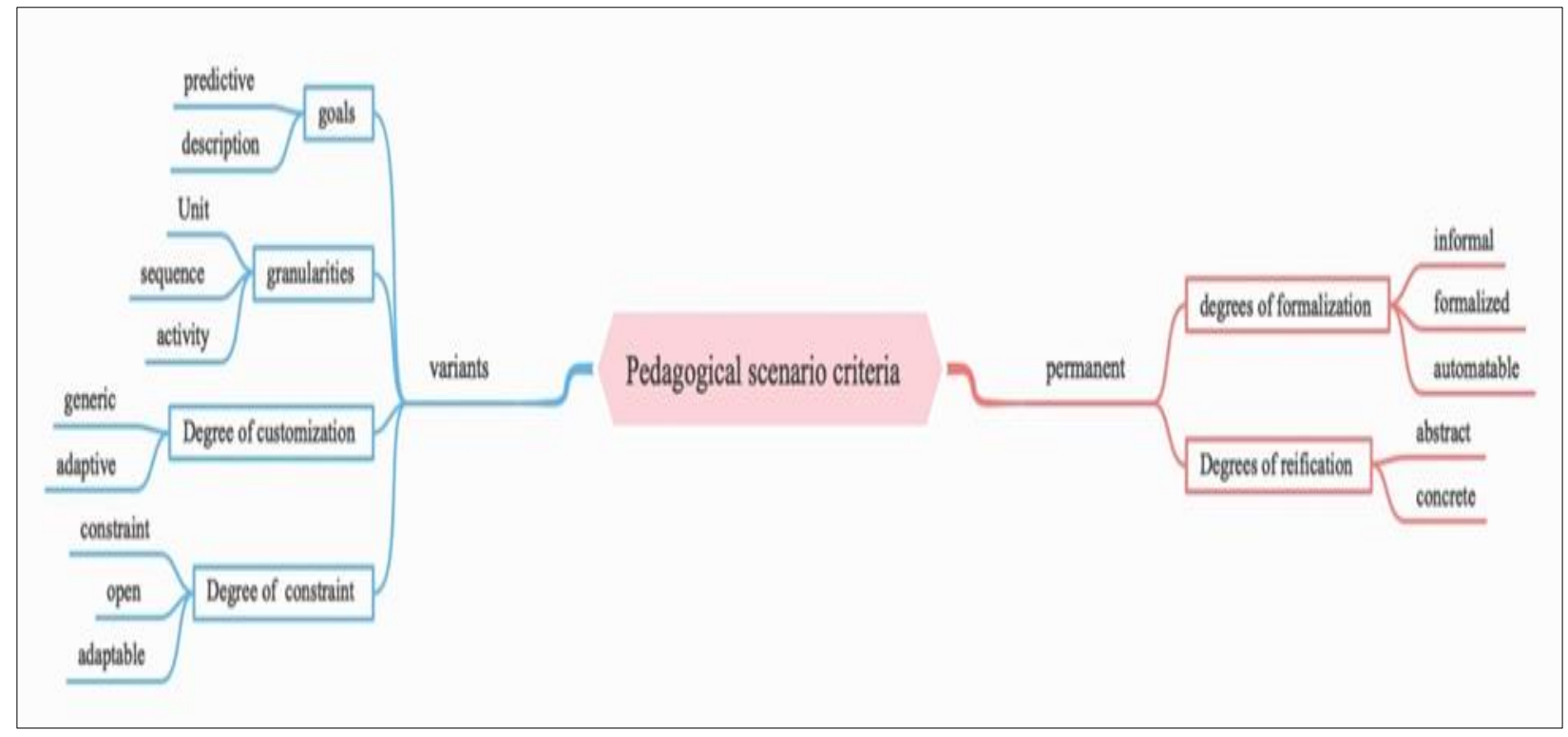

Figure 4 Criteria for characterizing a pedagogical scenario

To reify pedagogical scenarios, two types of scenarios must be taken into consideration: 
- Abstract scenarios describe the components of learning in abstract terms. It is only during the contextualization (instantiation) of the abstract scenario that the role can be assigned to natural persons, and the resources described in the summary to specific resources;

- The contextual scenario or specific scenario accurately describes the actual components associated with the abstract scenario in terms of assigning roles to natural persons, plans, knowledge resources, services, or providing tools.

\subsection{Learning scenario lifecycle}

In the study of any object, a distinction must be made between the original stage, the stage of use itself and the stage of evaluation, which make it possible to assess the contribution linked to its introduction. We define the scenario lifecycle as consisting of four main stages. The following figure illustrates the life cycle of a learning scenario.

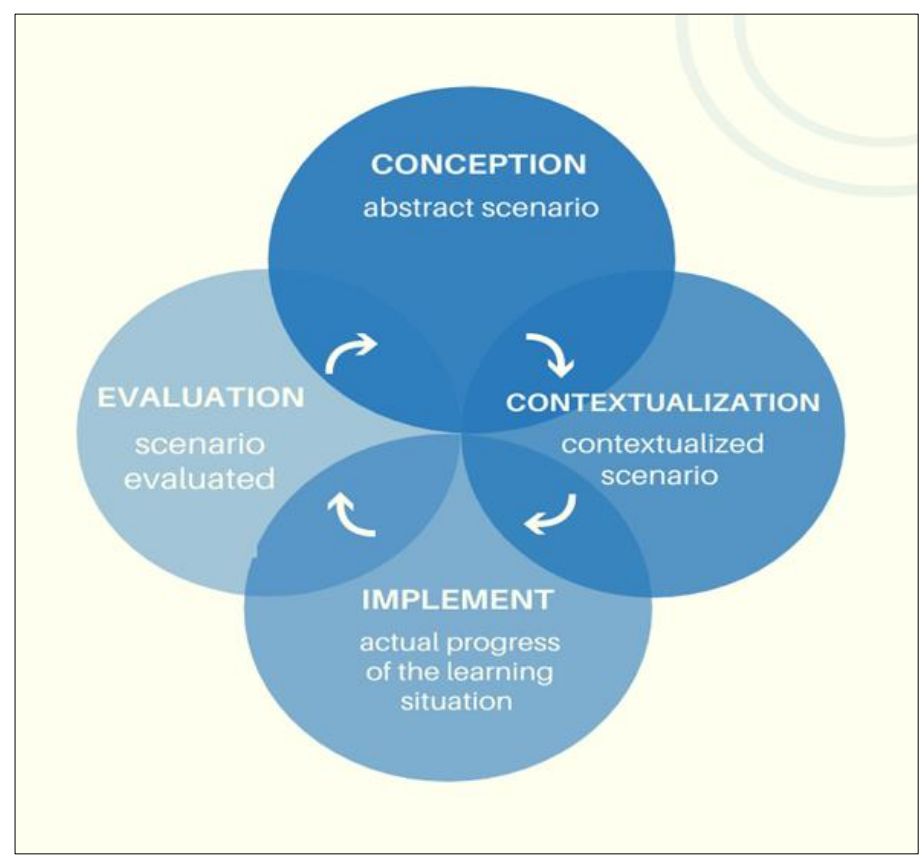

Figure 5 Pedagogical scenarios Life cycle

- The design phase defines the structure of the abstract scenario in general it does not take into account the precision of the implementation conditions. This first step define the a priori conditions, and generally the organization and course of the learning situation. The initial design phase result is an abstract scenario that does not take into account the exact conditions of implementation. This type of scene can be created from scratch or adjusted from pre-existing typical scenarios.

- The Contextualization phase determines the operating conditions of the abstract scenario in a specific context based on participants, plans, resources, tools, and services. It is a phase that makes it possible to define the conditions for established abstract situations in specific training situations. There are several types of contextual tasks:

- Assign roles: Specifies the name of the natural person who will assume the standard role defined in the abstract scene.

- Activities plan: must accurately set the conditions of each activity (timetable, start date, end date, weakness,solustion...);

- Mediatize the scenario: includes the creation, reuse or adaptation of knowledge manipulation resources necessary to carry out the activities. These resources (whether digital resources) can exist in advance or can be created according to the needs of the associated scenarios;

- Personalize: take into account learner profiles.

- The Implementation phase corresponds to the use of scenarios associated with participants (learners, teachers, mentors, etc.) in certain circumstances;

- The Evaluation phase is linked to the evaluation of the results obtained during the implementation phase of the scenario. One of the main objectives is to set the conditions for its further use in other situations.

- The following figure shows an example of a class diagram of a learning scenario. 


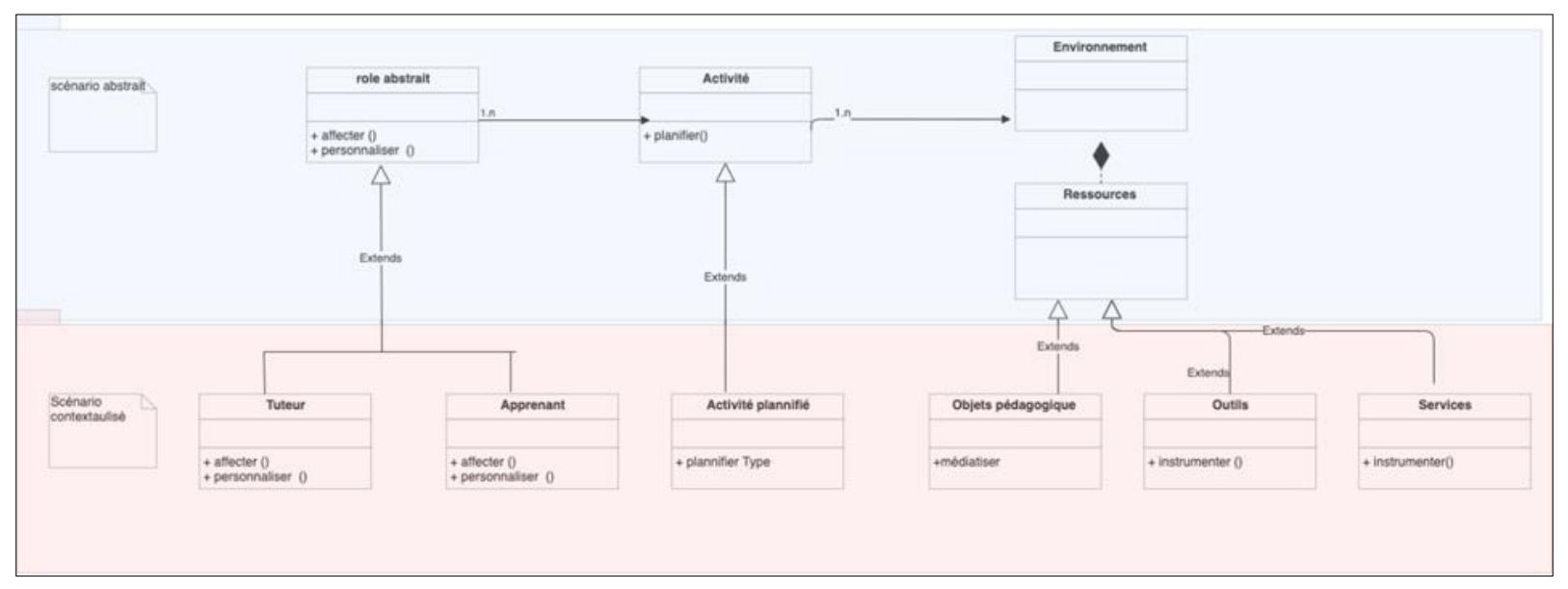

Figure 6 Ex class diagram example of a pedagogical scenario

\section{The learning cycle according to Kolb}

In our work we chose to use the Kolb model focuses on the theoretical and pedagogical aspects that affect the learning process on the one hand. On the other hand, Kolb's model believes that knowledge creation is the result of learners new experiences processing and internal cognitive processes, which take place through a four-step cycle based on experience [5].

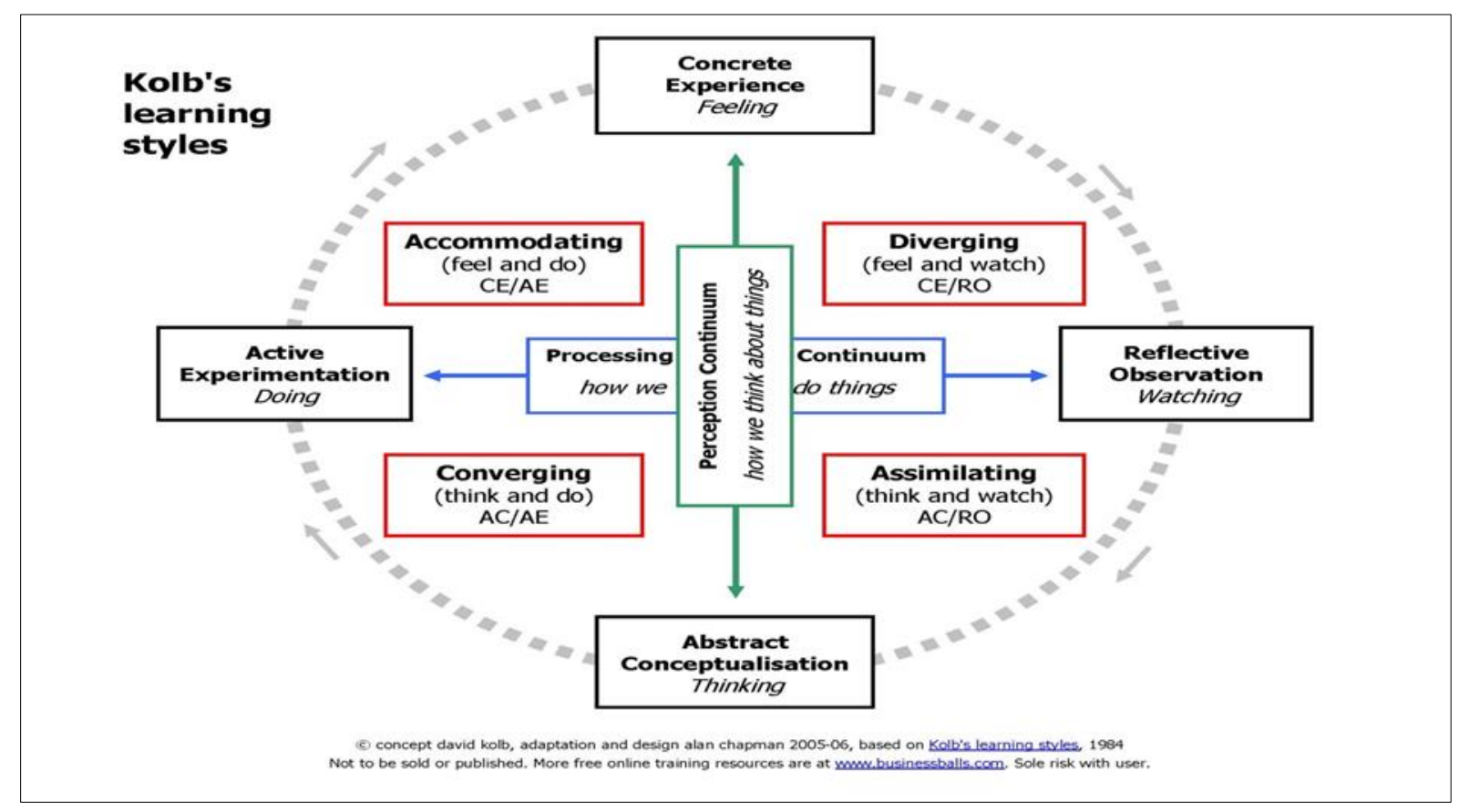

Figure 7 Kolb's learning cycle

In fact Kolb argues that learning requires abstract concepts that can be flexibly applied to various situations [21].In this theory, the development of new concepts is ensured by a new experience. He prefers that learners learn in cycles to advance their learning.

The learning approach adopted in the learning activities is based on the Kolb learning cycle. This approach is reflected in four distinct stages: engagement activity, conceptualization, objectification, transfer [22]. 


\subsection{Kolb's learning styles and conceptualization}

The following table gives us the different learning styles according to Kolb by defining the learning mode of each style and the corresponding learning method.

Table 8 Learning Methods by Learning Styles and Kolb's learning modes

\begin{tabular}{|l|l|l|}
\hline Learning style according to Kolb & Learning mode according to Kolb & Learning method \\
\hline Divergent & $\begin{array}{l}\text { a combination of hands-on experience and } \\
\text { reflective observation }\end{array}$ & $\begin{array}{l}\text { Learning through } \\
\text { "experience" }\end{array}$ \\
\hline Assimilate & $\begin{array}{l}\text { a combination of abstract conceptualization and } \\
\text { reflective observation. }\end{array}$ & $\begin{array}{l}\text { Prefers "theoretical } \\
\text { courses" }\end{array}$ \\
\hline Convergent & $\begin{array}{l}\text { a combination of abstract conceptualization and } \\
\text { active experimentation }\end{array}$ & $\begin{array}{l}\text { "Work on self-managed } \\
\text { projects and activities". }\end{array}$ \\
\hline Accommodate & $\begin{array}{l}\text { a combination of concrete observation and active } \\
\text { experimentation }\end{array}$ & $\begin{array}{l}\text { "Working in small } \\
\text { groups". }\end{array}$ \\
\hline
\end{tabular}

\subsection{Abstract pedagogical scenarios of the learning activities of the conceptualization phase according to Kolb's learning styles}

\subsubsection{Divergent Style: Deductive Presentation}

- The input system of the conceptualization / deductive presentation phase: The specific objectives of this sequence are presented so that the learner has a clear vision of his learning process.

- The learning system of the conceptualization / deductive presentation phase: Consists of going from the general to the particular by following these steps:

- Make a description and a general presentation of the concept;

- Give contextualized examples;

- Give application exercises with feedback!;

- The output system of the conceptualization / deductive presentation phase: A conclusion/balance sheet is presented.

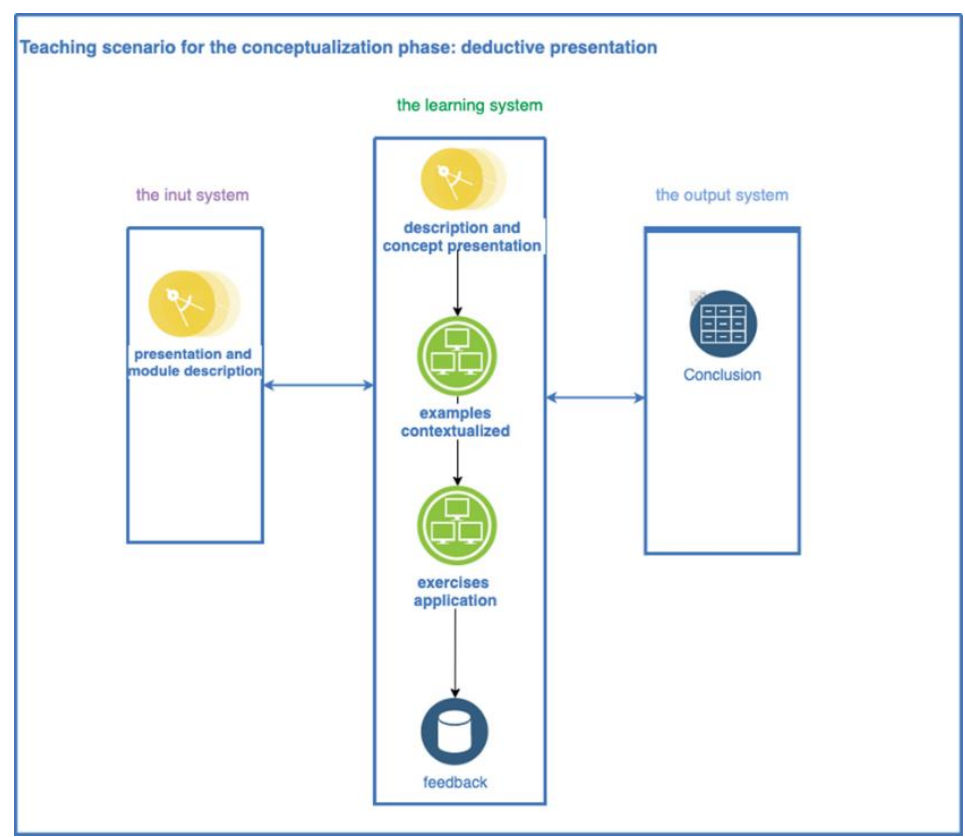

Figure 8 Pedagogical scenario of the deductive presentation for the divergent style 


\subsubsection{Assimilating style: inductive presentation}

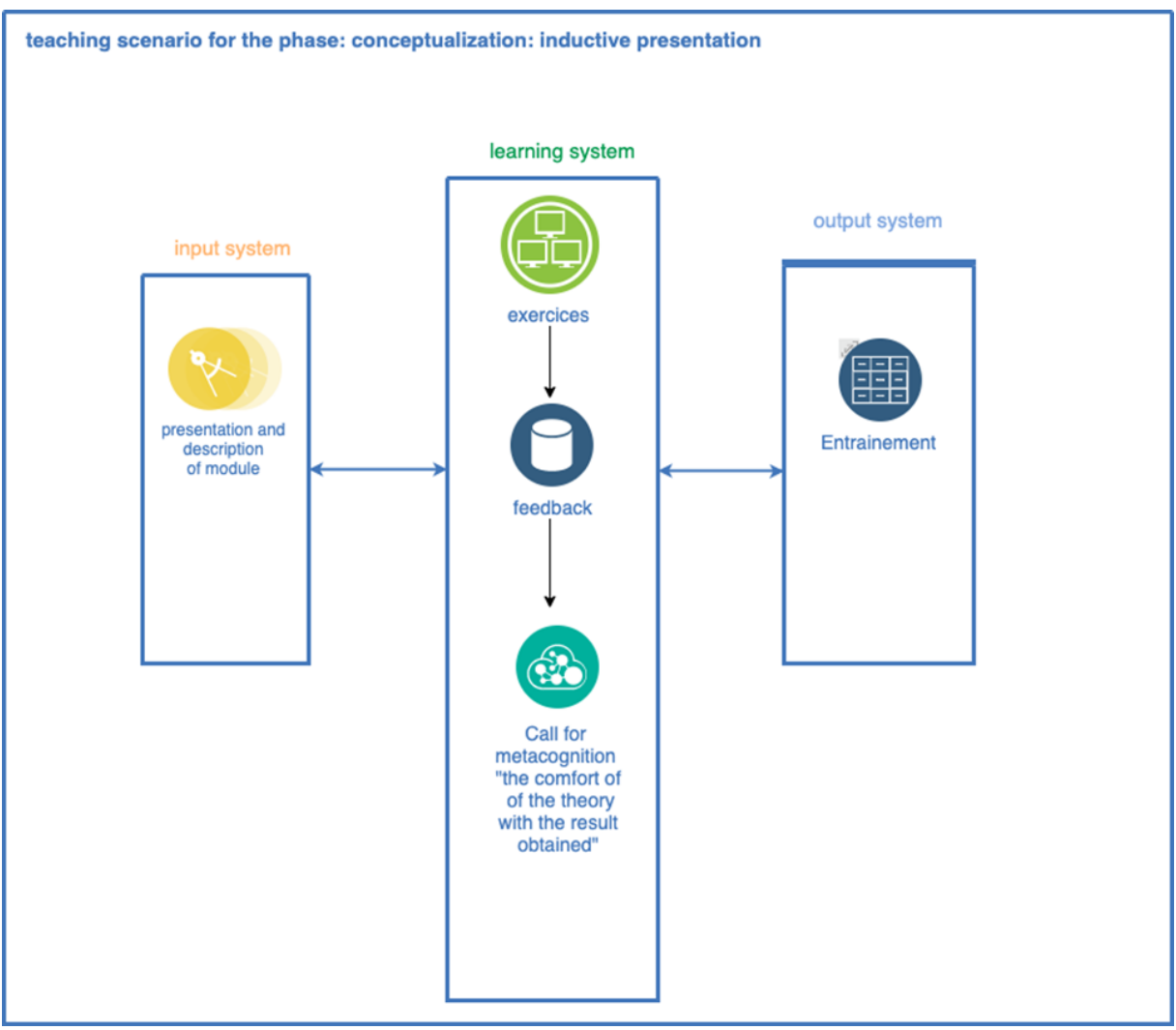

Figure 9 Pedagogical scenario of the inductive presentation for the assimilator style

- The input system of the conceptualization/inductive presentation phase: which in we present the specific objectives of this sequence so that the learner has a clear vision of his learning process.

- The learning system of the conceptualization / inductive presentation phase: which consist on going from the particular to the general by following these steps:

- Propose an exercise/experience with immediate feedback;

- Make a confrontation of the theory with the result obtained: call for metacognition.

- The output system of the conceptualization / inductive presentation phase: conclusion/balance is presented.

\subsubsection{Convergent style: self-managed project or activity}

- $\quad$ The entry system of the conceptualization phase / self-managed activities: which in we present the specific objectives of this sequence so that the learner has a clear vision of his learning process.

- The learning system of the conceptualization phase / self-managed activities: Idem at up of going from the particular to the general by following these steps:

- Propose an activity with immediate feedback;

- Gather the necessary resources and prepare documents adapted to the activity for use by the learner during the activity;

- Make a confrontation of the theory with the result obtained: call for metacognition.

The exit system of the conceptualization phase /self-managed activities: We present a conclusion/balance sheet . 
Global Journal of Engineering and Technology Advances, 2021, 09(01), 050-064

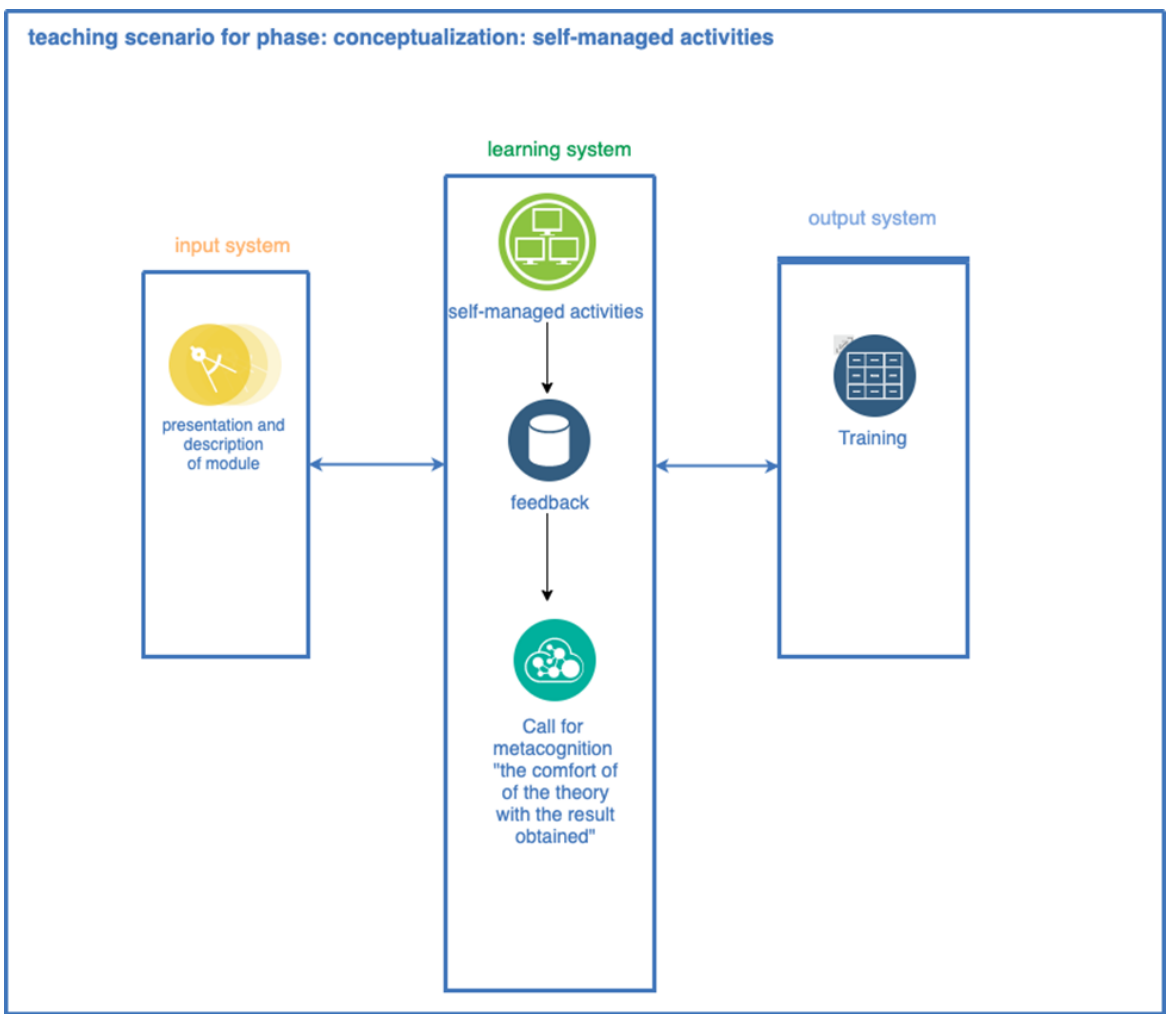

Figure 10 Project pedagogical scenario or self-managed activity for convergent style

4.2.4. Accommodation style: small group discussion

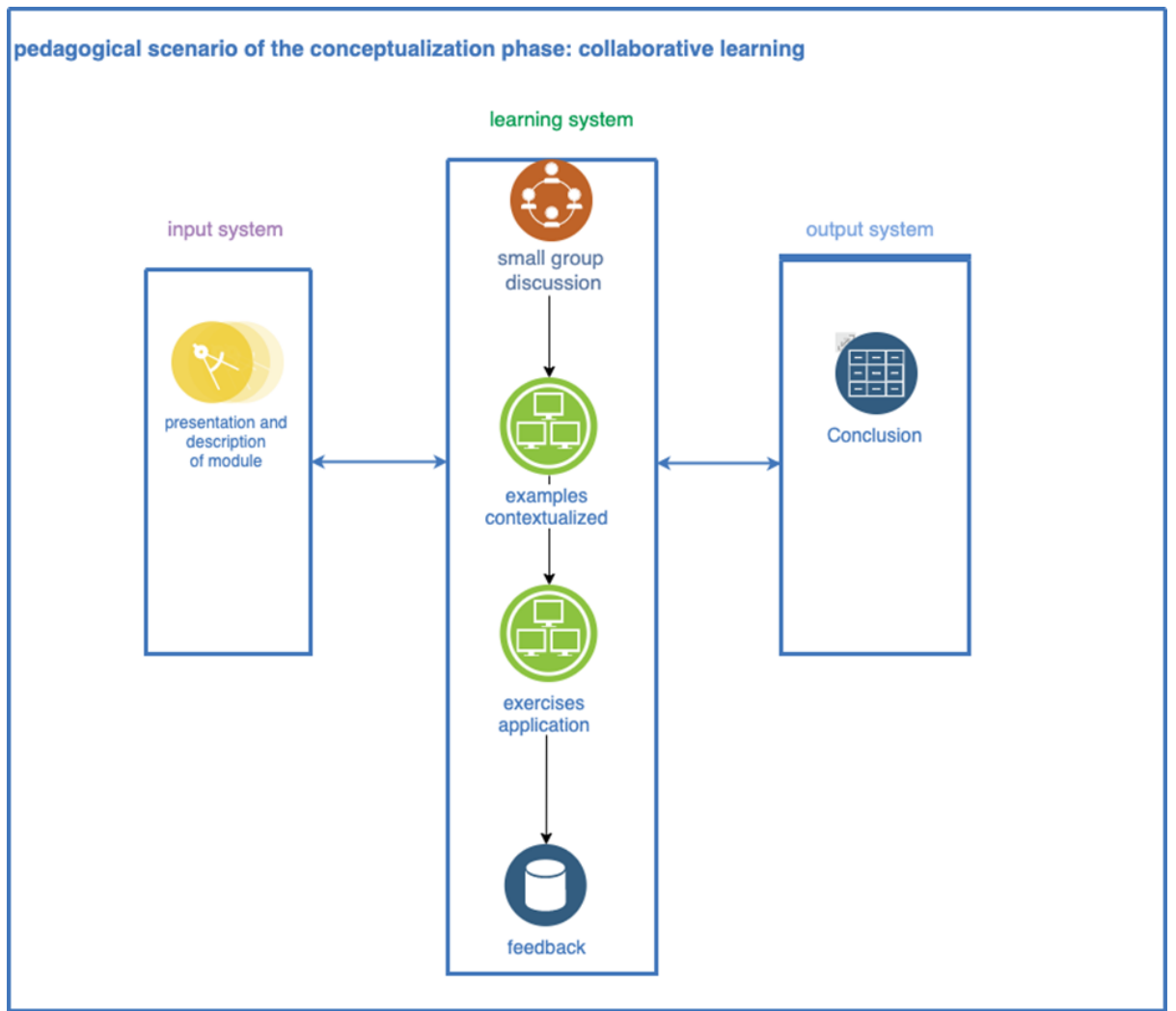

Figure 11 Pedagogical scenario of small group discussion for the accommodator style 
- The entry system of the conceptualization/collaborative learning phase: which in we present the specific objectives of this sequence so that the learner has a clear vision of his learning process.

- $\quad$ The learning system of the conceptualization/collaborative learning phase :

- Collaborative working method: discussion for example;

- $\quad$ Provide contextualized examples;

- $\quad$ Give application exercises with feedback.

The exit system of the conceptualization / collaborative learning phase: which in we present a conclusion/assessment

\section{Conclusion}

In this article we tried in the first part to present the existing learning styles by highlighting the main characteristics of each, in the second part we introduced the learning scenario based on the work and research of Pernin and Koper, we presented the taxonomy of pedagogical scenario, its characteristics (purpose, granularities, degrees of constraint, degrees of personalization, degrees of formalization, degrees of reification) and its life cycle of which we focused on the abstract design phase where the result is an abstract scenario, then in the third part we mentioned that the learning activity (the finest granularity) must take place in four stages: engagement activity, conceptualization, objectification, transfer. In this article, we have concentrated our work on conceptualization since it is the phase where the learner builds his knowledge, this construction differs from one learner to another according to his learning style, so we have tried to present four abstract learning scenarios divided into three systems (entry system, learning system, exit system) each is adequate to a LEARNING style of KOLB.

This article is a theoretical study which is based on THE LEARNING STYLES OF KOLB to classify the subjects according to their learning styles .

\section{Compliance with ethical standards}

\section{Acknowledgments}

None. No funding to declare.

\section{Disclosure of conflict of interest}

Waladi chaimae, Lamarti Sefian mohammed, Khaldi Mohamed declare that they have no conflict of interest.

\section{References}

[1] Sabine Graf,et al Supporting Teachers in Identifying Students' Learning Styles in Learning Management Systems: An Automatic Student Modelling Approach. Journal of Educational Technology \& Society. $2009 \mathrm{~b} ; 12$.

[2] T-CYG-JHSJ-HY. Development of an Adaptive Learning System with Multiple Perspectives based on Students' Learning Styles and Cognitive Styles. International Forum of Educational Technology \& Society. $2013 ; 16$.

[3] HPMMDDRRB. Learning Styles Concepts and Evidence PSYCHOLOGICALSCIENCE IN THE PUBLIC INTEREST. 2009; 9.

[4] Learning Styles - various approaches or ways of learning. The Peak Performance Center. 6 October 2015b.

[5] Kolb AY, Kolb DA. Learning Styles and Learning Spaces: Enhancing Experiential Learning in Higher Education. Academy of Management Learning \& Education. 2005; 4(2): 193-212.

[6] Doctoral College | Explore our research. University of Leicester. 14 May 2018.

[7] Graf S, Viola SR, Leo T, Kinshuk. In-Depth Analysis of the Felder-Silverman Learning Style Dimensions. Journal of Research on Technology in Education. 2007; 40(1): 79-93.

[8] HERRMANN N. The Creative Brain*. The Journal of Creative Behavior. 1991; 25(4): 275-295.

[9] Paquette G. Telelearning Engineering: Building Networked Learning, Sainte-Foy: Presses de l'Université du Québec. 2002.

[10] Daele A, Brassard C, Esnault L, Donoghue M, Uytterbrouk E, Zeiliger R. Design, implementation, analysis and evaluation of educational scenarios using ICT, Project Report Recre@sup-WP2 FUNDP. 2002. 
[11] Lando P. Progetto: a method for designing scenario templates for project-based remote collective pedagogical activities, DeA thesis, University of Picardy. 2003.

[12] Pernin J-P, Lejeune A. Models for the reuse of learning scenarios, Proceedings of the TICE Méditerranée conference, Nice. 2004.

[13] Guéraud V. Author approach for Active Learning Situations: Scenarios, Monitoring and Engineering, HDR, Joseph Fourier University, Grenoble. 2006.

[14] Koper R. From change to renewal: Educational technology foundations of electronic learning environments. Open University of the Netherlands.

[15] El-Moudden F, Aammou S, Khaldi M. A tool to generate a collaborative content compatible with IMS-LD. Int. J. Softw. Web Sci. December 2014-February 2015; 11(1): 01-08.

[16] Lejeune A. IMS Learning Design. Study of a pedagogical modeling language. Distances and Knowledge. 2004; 2(4): 409-450.

[17] PJP. Pedagogical objects: learning units, activities or resources. Educational Sciences and Techniques. Published. 2003.

[18] Pernin J.-Lejeune A. Learning devices instructed by technology: towards scenario-centred engineering. In: proceedings of the conferenceTICE, Compiègne (France). 2004; 407-414.

[19] Dessus p. The planning of teaching sequences, object of description or prescription? Revue Française de Pédagogie. 2000; 133(1): 101-116.

[20] Koper R. Modeling units of study from a pedagogical perspective. The pedagogical meta- model behind EML. Open University of the Netherlands. 2004.

[21] Dunn R, Griggs SA, Olson J, Beasley M, Gorman BS. A Meta-Analytic Validation of the Dunn and Dunn Model of Learning-Style Preferences. The Journal of Educational Research. 1995; 88(6): 353-362.

[22] Kolb DA. Experiential learning. Englewood Cliffs, New Jersey: Prentice-Hall. 1984. 